\section{BMJ Open \\ Respiratory Research}

\title{
Design of the Subpopulations and Intermediate Outcome Measures in COPD (SPIROMICS) AIR Study
}

Nadia N Hansel, ${ }^{1}$ Laura M Paulin, ${ }^{1}$ Amanda J Gassett, ${ }^{2}$ Roger D Peng, ${ }^{3}$ Neil Alexis, ${ }^{4}$ Vincent S Fan, ${ }^{2,5}$ Eugene Bleecker, ${ }^{6}$ Russell Bowler, ${ }^{7}$ Alejandro P Comellas, ${ }^{8}$ Mark Dransfield, ${ }^{9}$ MeiLan $\mathrm{K} \mathrm{Han},{ }^{10}$ Victor Kim, ${ }^{11}$ Jerry A Krishnan, ${ }^{12}$ Cheryl Pirozzi, ${ }^{13}$ Christopher B Cooper, ${ }^{14}$ Fernando Martinez, ${ }^{15}$ Prescott G Woodruff, ${ }^{16}$ Patrick J Breysse, ${ }^{17}$ R Graham Barr, ${ }^{18}$ Joel D Kaufman ${ }^{2}$

To cite: Hansel NN, Paulin LM, Gassett AJ, et al. Design of the Subpopulations and Intermediate Outcome Measures in COPD (SPIROMICS) AIR Study. BMJ Open Resp Res 2017;4:e000186. doi:10.1136/ bmjresp-2017-000186

Received 23 March 2017 Accepted 29 March 2017

\section{CrossMark}

For numbered affiliations see end of article.

Correspondence to Dr Nadia N Hansel; nhansel1@jhmi.edu

\section{ABSTRACT}

Introduction Population-based epidemiological evidence suggests that exposure to ambient air pollutants increases hospitalisations and mortality from chronic obstructive pulmonary disease (COPD), but less is known about the impact of exposure to air pollutants on patient-reported outcomes, morbidity and progression of COPD.

Methods and analysis The Subpopulations and Intermediate Outcome Measures in COPD (SPIROMICS) Air Pollution Study (SPIROMICS AIR) was initiated in 2013 to investigate the relation between individual-level estimates of short-term and longterm air pollution exposures, day-to-day symptom variability and disease progression in individuals with COPD. SPIROMICS AIR builds on a multicentre study of smokers with COPD, supplementing it with state-of-the-art air pollution exposure assessments of fine particulate matter, oxides of nitrogen, ozone, sulfur dioxide and black carbon. In the parent study, approximately 3000 smokers with and without airflow obstruction are being followed for up to 3 years for the identification of intermediate biomarkers which predict disease progression. Subcohorts undergo daily symptom monitoring using comprehensive daily diaries. The air monitoring and modelling methods employed in SPIROMICS AIR will provide estimates of individual exposure that incorporate residence-specific infiltration characteristics and participant-specific time-activity patterns. The overarching study aim is to understand the health effects of short-term and longterm exposures to air pollution on COPD morbidity, including exacerbation risk, patient-reported outcomes and disease progression.

Ethics and dissemination The institutional review boards of all the participating institutions approved the study protocols. The results of the trial will be presented at national and international meetings and published in peer-reviewed journals.

\section{INTRODUCTION}

Chronic obstructive pulmonary disease (COPD) is a leading cause of death worldwide, and its prevalence is expected to increase. ${ }^{1}$ Individuals with COPD suffer high morbidity, including poor quality of life, activity limitation and exacerbations. A better understanding of contributing factors to the development, progression and burden of this pervasive disease is critical. COPD is largely attributable to the total burden of toxic gases and particles that individuals inhale during their lifetimes. While the primary exposure in the USA is cigarette smoke, ambient air pollution, including particulate matter air pollution, has also been associated with lower lung function and higher incidence of COPD. ${ }^{2}$ Population-based epidemiological evidence suggests that exposure to ambient air pollutants increases hospitalisations and mortality from COPD ${ }^{2}$ but little is known about the impact of exposure to air pollutants on the progression of COPD. Both outdoor and indoor air pollution may accelerate lung function loss in individuals with COPD, impact health status and lead to exacerbations that represent substantial patient burden but do not require hospitalisation.

The Subpopulations and Intermediate Outcome Measures in COPD Study (SPIROMICS) is a unique longitudinal National Heart, Lung, and Blood Institute (NHLBI)-funded prospective cohort study designed to identify subpopulations and intermediate outcome measures in individuals with COPD. SPIROMICS enrolled 1836 current and former smokers with COPD (strata III and IV), 944 smokers without airflow obstruction (stratum II), and 202 non-smoking controls (stratum I) across cities in the USA. The purpose of the SPIROMICS Air Pollution Study (SPIROMICS AIR) is to add state-of-the art air pollution exposure assessment to estimate individual-level outdoor and indoor air pollution exposures 
for all SPIROMICS participants, providing an extraordinary opportunity to understand the effects of multiple air pollutants on COPD morbidity and progression.

\section{METHODS}

\section{Study objectives and study design}

SPIROMICS AIR has three primary objectives: (1) to analyse the impact of outdoor and indoor air pollutants, including particulate matter with aerodynamic diameter less than $2.5 \mu \mathrm{m}\left(\mathrm{PM}_{25}\right)$, nitrogen dioxide $\left(\mathrm{NO}_{2}\right)$, nitrogen oxides $\left(\mathrm{NO}_{\mathrm{x}}\right)$, sulfur dioxide $\left(\mathrm{SO}_{2}\right)$, ozone $\left(\mathrm{O}_{3}\right)$, black carbon $(\mathrm{BC})$ and second-hand smoke on COPD morbidity over 3 years; (2) to determine whether short-term changes in outdoor air pollution concentrations $\left(\mathrm{PM}_{2.5}, \mathrm{NO}_{2}\right)$ are associated with day-to-day changes in COPD morbidity (respiratory symptoms, risk of exacerbations); and (3) to examine airway macrophage (AM) BC content from induced sputum as a potential biomarker of traffic-related air pollution ( $\mathrm{PM}_{2.5}$ and $\left.\mathrm{BC}\right)$ and determine its association with clinical and subclinical measures of disease severity and progression in individuals with COPD.

Each objective involves rigorous, participant-specific characterisation of air pollution exposures. Cohort-specific air monitoring was conducted to support the development of air pollution prediction models that can be generalised to the study population over the course of follow-up. These models are based on sophisticated spatio-temporal air pollution prediction methods developed in Multi-Ethnic Study of Atherosclerosis and Air Pollution (MESA Air) ${ }^{3}$ that incorporate the study-specific outdoor monitoring data, nearby regulatory air monitoring data and geographic information about each location. Spatio-temporal predictions are generated as 2-week averages, and are primarily intended to be analysed in association with chronic outcomes such as decline in forced expiratory volume $\left(\mathrm{FEV}_{1}\right)$, patient-reported outcomes and frequency of exacerbation.

Daily variation in air pollutants, which are the primary exposure for objective 2 and necessary as validation metrics for objective 3 , will be based on daily measurements collected at regulatory agency monitoring locations. Daily $\mathrm{PM}_{2.5}$ and $\mathrm{NO}_{2}$ will be linked to daily symptoms recorded in a subset of subjects with COPD over a 1-year period who participated in the SPIROMICS Exacerbation Substudy. The Exacerbation Substudy enrolled 217 subjects and captured respiratory symptoms using a daily electronic diary (EXAcerbations of Chronic pulmonary disease Tool (EXACT) Patient-Reported Outcome $($ EXACT-PRO $))^{4}$ for up to 1 year per subject. For aim 3, daily measurements of $\mathrm{BC}$ and $\mathrm{PM}_{2.5}$, 2-week spatio-temporal predictions of $\mathrm{BC}$ and $\mathrm{PM}_{2.5}$, and proxies of traffic exposure such as distance between the residence and the nearest major road will be compared with AM BC. AM BC will be assessed in up to 1000 participants with acceptable quality of induced sputum collected at baseline.
The institutional review boards of all the participating institutions approved the study protocols.

\section{Study population}

Subjects for SPIROMICS were enrolled, phenotyped and followed at multiple clinical centres (Winston-Salem, North Carolina; Ann Arbor, Michigan; San Francisco, California; Los Angeles, California; New York City (NYC), New York; Salt Lake City, Utah; Baltimore, Maryland; Denver, Colorado; Iowa City, Iowa; Birmingham, Alabama; Chicago, Illinois; and Philadelphia, Pennsylvania) from 2010 through 2016. Participants were 40-80 years of age at baseline, who were either healthy persons with a smoking history of $\leq 1$ pack-year and no known current lung disease $(n=202)$ or current or former smokers ( $\geq 20$ pack-years) with and without evidence of obstructive lung disease. Current and former smokers were categorised as having either no spirometric evidence of airflow obstruction $(\mathrm{n}=941)$, or having COPD (postbronchodilator $\mathrm{FEV}_{1} / \mathrm{FVC}<70 \%$ with Global Initiative for Chronic Obstructive Lung Disease (GOLD) stage I/ II $\left(\mathrm{FEV}_{1} \geq 50 \%\right.$ predicted; $\left.\left.\mathrm{n}=1207\right)\right)$ or GOLD stage III/ IV $\left(\mathrm{FEV}_{1}<50 \%\right.$ predicted; $\left.\mathrm{n}=624\right)$ disease. Current or former smokers with a concomitant diagnosis of asthma were not excluded, but individuals with other non-COPD obstructive lung disease, body mass index (BMI) $>40 \mathrm{~kg} /$ $\mathrm{m}^{2}$ at baseline or diagnosis of unstable cardiovascular disease were excluded. Individuals with prior history of chest surgery or metallic implants in the thorax were excluded due to impact on chest CT interpretation.

SPIROMICS also includes substudies that greatly complement the goals of the current proposal. The Exacerbation Substudy was designed to provide novel insight into the biology of COPD exacerbations and uses a validated daily electronic tool to measure respiratory symptoms (EXACT; EXACT-PRO). ${ }^{4}$ This allows for the capture of daily respiratory symptoms as well as capture of symptom-based respiratory exacerbations that may not have led to 'traditional' healthcare utilisation-defined events.

\section{Clinical phenotyping and data collection Clinical data}

Clinical data were collected as part of the main SPIROMICS study. Spirometry before and after bronchodilator was performed according to standard guidelines ${ }^{5}$; all pulmonary function tests were monitored for quality control and assurance. Exacerbations were assessed prospectively by quarterly phone calls and yearly visits. Any exacerbation was defined as worsening respiratory symptoms requiring antibiotics or oral steroids. Severe exacerbations were those leading to an emergency department visit or hospitalisation. Hospitalised events, mortality and cause of death will be adjudicated by the Morbidity and Mortality Subcommittee. Additional patient-reported outcomes included health status determined using the St. George's Respiratory Questionnaire 
and COPD Assessment Test. ${ }^{7}$ Dyspnoea was assessed using the Modified Medical Research Council Dyspnea Scale $^{8}$ and functional exercise capacity was assessed by the 6 min walk test, performed according to American Thoracic Society (ATS) criteria. ${ }^{9}$ These measures were collected annually for up to 3 years. In addition, at the baseline and 1-year follow-up study visits, participants underwent whole-lung multidetector helical CT at full inspiration and expiration for measurements including per cent emphysema (\% Hounsfield units (HU) $<950$ at total lung capacity), per cent gas trapping $(\% \mathrm{HU}<856$ at residual volume and airway dimensions (Pi10 averaged for the whole lung and over a sequence of five airway segments) ) following a highly standardised protocol. ${ }^{10}$

\section{$\mathrm{BC}$ in $\mathrm{AMs}$}

Preserved induced sputum cytospin slides have been collected as part of the SPIROMICS study. Cytospin samples were prepared from whole sputum samples that were treated with dithiothreitol $(0.1 \%)$, filtered, then stained with trypan blue and counted on a haemocytometer to determine the total viable leucocytes present in the sample. Cytospin slides were generated, fixed and stained for microscopic examination of leucocyte populations. Acceptable quality slides will be chosen for BC analysis based on evidence of good cell morphology (minimal cell degeneration), minimal cell debris, good quality staining, satisfactory cell dispersion and minimal squamous epithelial cell contamination. AMs will be visualised by light microscopy at $\times 100$ magnification. Briefly, 50 AMs per slide will be randomly selected by a trained technician blinded to environmental exposure assessments and clinical outcomes and the area occupied by black material (carbon) in each macrophage will be quantified as previously described. ${ }^{11} 12$

\section{Air quality assessment and environmental data collection}

\section{Residential address history and geocoding}

The main SPIROMICS study collected a 10-year residential history at baseline and obtained address changes during quarterly follow-up calls and annual clinic visits. Addresses were geocoded at the University of Washington using ArcGIS 10.3, which preferentially places addresses according to parcel data (property delineation data). Addresses not matched to a parcel may be estimated using an automated procedure which calculates the location of a house number. If no house number is available, then the address is given the location of the nearest intersection or middle of the length of the street. Failing one of these methods, the residence is placed at the zip code centroid. Since automated geocoding typically places locations on the centreline of roads, a $9 \mathrm{~m}$ offset was applied. ${ }^{13}$ Addresses not able to be placed at any of these locations are not given a location and were omitted from subsequent analyses.
Housing characteristics and time-location behaviour

A Home Information Questionnaire (HIQ) was administered to each participant once during the study either in person or over the phone during a routine follow-up visit or call. The questionnaire is modified from the MESA Air $\mathrm{HIQ}^{14}$ and includes questions about predictors of indoor air pollution, which assess building characteristics, heating and air conditioning use, window opening behaviours, indoor air pollution sources, use of combustion sources and time-location patterns. The HIQ has previously been shown to have good agreement with a behaviour log administered at the time of home air monitoring. ${ }^{15}$

\section{Environmental data and air pollution model predictions for} chronic outcomes

Outdoor concentrations of $\mathrm{PM}_{25}, \mathrm{NO}_{2}, \mathrm{NO}_{\mathrm{x}}, \mathrm{O}_{3}, \mathrm{SO}_{2}$ and $\mathrm{BC}$ outside of each participant's home are estimated using spatio-temporal modelling methods developed in MESA Air. ${ }^{16}{ }^{17}$ Briefly, long-term air pollution trends are estimated from measurements collected at United States Environmental Protection Agency (EPA) Air Quality System (AQS) monitoring sites and other long-term monitoring locations. Partial least squares regression (PLSR) is used to create covariates that combine geographic variables including land use, distance to roadways, vegetative cover, impervious surface cover, traffic data, population and elevation. Spatially varying coefficients for the time trends are estimated using these PLSR covariates and spatial smoothing, essentially predicting the longterm mean and scale of temporal variation based on point-specific characteristics. The model benefits from spatially rich supplemental monitoring data that are leveraged to estimate the spatially varying coefficients and determine the structure of the spatio-temporal residual field. These data include the cohort-focused monitoring conducted by SPIROMICS AIR, pollutant concentrations previously measured by the MESA Air study in the four overlapping regions (Baltimore, NYC, Los Angeles and Winston-Salem), and those measured by the New York City Community Air Study. ${ }^{18}$ Two types of outdoor air monitoring were performed in SPIROMICS Air cities: (1) community 'snapshot' and (2) residential. These methods allow additional spatial coverage relevant to this cohort not available from existing datasets.

\section{Community 'snapshot' monitoring}

Community 'snapshot' monitoring was conducted in each of two seasons in three of the primary study regions (Ann Arbor, San Francisco, Salt Lake City) to capture small-scale spatial variations in pollutant concentrations while minimising temporal confounding. In the four communities previously monitored in MESA Air (Los Angeles, NYC, Baltimore, Winston-Salem), one monitoring campaign was performed to confirm spatial stability and understand secular trends in exposures. These 'snapshot' sampling events (table 1) include 


\begin{tabular}{|c|c|c|c|c|c|c|c|c|c|c|c|c|c|c|c|}
\hline 2013 & & & & 2014 & & & & 201 & & & & 2016 & & & \\
\hline Q1 & Q2 & Q3 & Q4 & Q1 & Q2 & Q3 & Q4 & Q1 & Q2 & Q3 & Q4 & Q1 & Q2 & Q3 & Q4 \\
\hline
\end{tabular}

Visit $2(n=2350)$

Visit $3(n=1492)$

Visit $4(n=894)$

HIQ administered $(n=1938)^{\star}$

Environmental monitoring

Baltimore

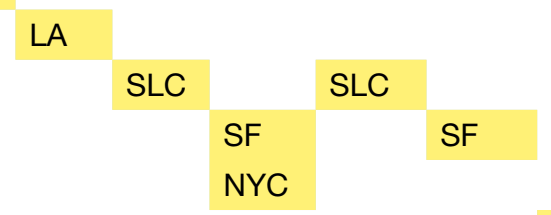

AA

AA

W-S

Sites: AA (Ann Arbor, Michigan); LA (Los Angeles, California); NYC (New York City, New York); SF (San Francisco, California); SLC (Salt Lake City, Utah); W-S (Winston-Salem, North Carolina).

${ }^{*} \mathrm{HIQ}$ administered once to each participant by in-person or telephone interview. 1936 is the total number administered as of 1 September 2016.

HIQ, Home Information Questionnaire; SPIROMICS, Subpopulations and Intermediate Outcome Measures in COPD Study.

simultaneous deployment of passive air monitors at 100 locations, which are selected to oversample local sources of traffic, and placed on stationary objects such as telephone poles adjacent to major roadways. This sampling effort provides integrated 2-week samples of $\mathrm{NO}_{2}, \mathrm{NO}_{\mathrm{x}}$, $\mathrm{SO}_{2}$ and $\mathrm{O}_{3}$.

\section{Residential monitoring}

At subsets of approximately 30 participants' residences in each of the seven primary SPIROMICS study regions (220 locations total), 2-week integrated measurements were collected inside and outside participants' homes. We measured outdoor concentrations of $\mathrm{PM}_{2.5}$ and $\mathrm{BC}$ using active sampling, and $\mathrm{NO}_{2}, \mathrm{NO}_{\mathrm{x}}, \mathrm{O}_{3}$ and $\mathrm{SO}_{2}$ using passive monitoring. ${ }^{19}$ Participants also wore passive samplers for $\mathrm{NO}_{2}, \mathrm{NO}_{\mathrm{x}}, \mathrm{O}_{3}$ and $\mathrm{SO}_{2}$ to inform the comparability of home exposure to total exposure.

\section{Environmental data for daily symptoms and exacerbations}

Short-term pollutant exposures are estimated as the concentration measured at a central site within the EPA AQS network on the day prior, 2 days prior and 3 days prior to the patient-reported acute outcomes.

\section{Assessment of relationship between exposures and respiratory health}

For objective 1, longitudinal analysis will test the effect of outdoor and indoor pollutant exposures on health outcomes with the primary outcome of interest being rate of change of $\mathrm{FEV}_{1}$ over the study period. The outcome will be treated as a normal random variable and a linear generalised estimating equation model with exchangeable correlation will be used to relate it to air pollutants and potential confounders while accounting for within-person variation. Additional outcomes will include exacerbations, mortality, CT phenotypes, health status and other patient-reported outcomes. Models will be constructed with and without adjustment for potential confounders, which will include social factors (eg, socioeconomic status) and baseline predictors that have previously been shown to explain variability in the health outcomes, including sex, age and study site. Time-varying covariates will include meteorological factors (temperature, humidity), seasons of sampling, smoking status, medication use and additional exposures such as occupational exposures. Effect modification will be explored by including interaction terms in the primary regression models. For example, smoking status will be analysed as a confounder and potential effect modifier.

For the study of short-term association of air pollution with exacerbations and symptoms, log-linear Poisson-distributed lag-time series models will be used to estimate the association between pollution and health. We will focus on 0-3 day lags of exposure as previous work in this area has suggested this is where health effects tend to be concentrated. ${ }^{20}$ In addition to person-specific confounder variables, visit-specific potential confounders such as season, ambient temperature and humidity will be included. Active smoking status and intensity will be analysed as confounders and potential effect modifiers. 


\section{Analysis of AMI BC as an exposure biomarker}

We will examine the relationship between $\mathrm{BC}$ content of AMs and our modelled individual exposure to both $\mathrm{PM}_{2.5}$ and $\mathrm{BC}$, and then investigate the association between $\mathrm{BC}$ content of AM and health outcomes. Associations between modelled exposures and AM measurements will be adjusted for factors such as age, sex, race/ethnicity, severity of illness, time since last exacerbation, meteorology, smoking and BMI. Clinical outcomes of interest include lung function, quantitative CT phenotypes and patient-reported outcomes. To explore possible effect modification, we will conduct stratified analysis by disease severity.

\section{DISCUSSION}

SPIROMICS AIR will use state-of-the-art exposure assessment methodologies in order to understand the effect of outdoor and indoor air pollution on the long-term progression of COPD, short-term day-to-day variability in symptoms, and evaluate a potential sputum biomarker of exposure and disease. This study is needed due to the large degree of uncertainty regarding the potential relationship between exposure to air pollution and COPD progression, symptoms and quality of life.

Outdoor air pollution has been linked to exacerbations and mortality in people with chronic respiratory disease. ${ }^{21}{ }^{22}$ Population-based studies suggest that outdoor PM concentrations are associated with a more rapid decline in lung function, ${ }^{23}$ greater per cent emphysema $^{24}$ and an increase in COPD hospitalisations and mortality, ${ }^{20} 25$ and outdoor $\mathrm{NO}_{2}$ concentrations are linked to increased risk of developing COPD and higher rates of exacerbations. ${ }^{25-28}$ A study of 399 subjects with COPD due to alpha-1 proteinase inhibitor deficiency suggested that a $10 \mu \mathrm{g} / \mathrm{m}^{3}$ increase in $\mathrm{PM}_{10}$ was associated with an extra $30 \mathrm{~mL} /$ year decline in $\mathrm{FEV}_{1}{ }^{29}$ Whether these findings extend to patients with COPD without alpha-1 proteinase inhibitor deficiency and whether the association of PM is modified by other clinical or environmental factors are unknown. SPIROMICS AIR allows for the longitudinal assessment of the effect of air pollution on COPD progression on a variety of outcomes, including validated COPD-specific outcomes, while allowing for adjusting and testing of effect modification by a variety of factors.

In addition to studying effects of long-term exposure to outdoor air pollution on progression of COPD, shortterm effects are also still uncertain as existing studies investigating short-term variation in pollution and COPD morbidity have been inconsistent and interpretations limited by small sample size. For example, some studies have shown a link between pollutant exposures and decreased $\mathrm{FEV}_{1}$ or peak expiratory flow ${ }^{21} 2230$ whereas others have not. ${ }^{26}{ }^{31}$ Similarly, the effect of short-term variability in pollutants on exacerbations and respiratory symptoms also remains unclear. In 94 subjects with $\mathrm{COPD}$, higher $\mathrm{PM}_{10}$ concentrations were linked to more dyspnoea and exacerbations, but no consistent association was found for other symptoms and no associations were found for other pollutants, including $\mathrm{NO}_{2}, \mathrm{O}_{3}$ or $\mathrm{SO}_{2} \cdot{ }^{26}$ Another panel study including subjects with $\mathrm{COPD}$ and asthma showed adverse respiratory health effects that included respiratory symptoms of coarse PM but not $\mathrm{PM}_{2.5}$ or $\mathrm{NO}_{2}{ }^{32}$

Studies assessing risk of exacerbations have relied on defining exacerbations by healthcare events such as prescription of systemic corticosteroids, antibiotics or unscheduled visits to a healthcare provider. However, using an event-based definition may miss a significant number of COPD exacerbations that are unreported but nonetheless are associated with worsening symptoms and health status. ${ }^{33}$ In addition, previous published studies suggest that a lag of 1-3 days may exist between increasing pollutant concentrations and risk of an exacerbation ${ }^{34}$; however, it is known that COPD exacerbations follow distinct, but varying, patterns of onset and recovery. ${ }^{35} \mathrm{We}$ will investigate whether short-term changes in outdoor air pollution $\left(\mathrm{PM}_{2.5}, \mathrm{NO}_{2}\right)$ are associated with day-to-day changes in COPD symptoms among the subset of subjects enrolled in the SPIROMICS exacerbations substudy. Given the extensive clinical characterisation afforded by SPIROMICS, we will be uniquely positioned to examine the time course of pollutant exposure and the initial onset as well as trajectory of symptom development leading to a reported exacerbation. Similarly, we will explore whether pollutant concentrations affect the varying courses of symptom improvement following exacerbations.

In addition to advancing our understanding of outdoor air pollution on variability of COPD symptoms and COPD progression, SPIROMICS AIR will aim to investigate the effects of indoor air pollution on COPD. Americans, particularly older individuals, spend the vast majority of time indoors $(87 \%),{ }^{36}$ and individuals with COPD spend more time at home than their age-matched counterparts. ${ }^{37}$ Even in homes where biomass is not used as a heating or cooking source, indoor $\mathrm{PM}_{2.5}$ concentrations may be associated with worse health status, ${ }^{38}$ and among former smokers with moderate-severe COPD living in the Baltimore-Washington area, indoor $\mathrm{PM}_{2.5}$ concentrations were shown to be associated with increases in COPD morbidity. ${ }^{39}$ Importantly, indoor air pollution is due to both indoor pollutant sources and to infiltration of outdoor air pollutants. Using the individual residential characteristics collected from the home information questionnaire completed by the majority of SPIROMICS participants in combination with meteorological data, we will be able to predict home infiltration efficiency, and predict indoor concentrations regardless of the region of residence. Understanding the potential role of indoor air pollution on COPD outcomes at the individual level is particularly important for indoor air since, unlike outdoor air, it can be modified. This would allow disease management strategies to emphasise reduction of pollutant exposure in the patient's home. 
As we characterise the role of outdoor and indoor air pollution in contributing to COPD outcomes and progression, it becomes increasingly important to identify potential biomarkers of pollutant exposure. Black-pigmented material in airway macrophages (AM) is carbonaceous in nature, and recent literature suggests that a dose-response relationship may exist between this biomarker and PM exposure in healthy controls. ${ }^{11}{ }^{40} \mathrm{In}$ addition, recent work by Belli et alsuggests that BC in AM found in induced sputum may be highly correlated with indoor, but not outdoor, PM in subjects with COPD. ${ }^{12}$ It remains to be shown whether the carbon content of AMs reflects long-term or short-term exposure to PM and what is the relative contribution of different exposures to AM BC content. The accumulation of BC may lead to inflammation, double-stranded DNA breaks and emphysema in mice, ${ }^{41}$ and may at least partly explain adverse health outcomes of pollution seen in smokers and non-smokers. Access to banked sputum samples as part of SPIROMICS permits an unprecedented evaluation of this novel measure as a biomarker of pollution exposure.

In summary, the NHLBI-funded SPIROMICS observational study, combined with state-of-the-art air pollution exposure assessment methods, provides an extraordinary opportunity for groundbreaking advances in understanding the contribution of environmental factors to COPD progression and disability.

SPIROMICS AIR will have the benefit of being able to link modelled pollutant concentrations to the extensive participant data collected as part of the SPIROMICS study, enabling the exploration of underlying mechanistic underpinnings to the adverse outcomes resulting from pollution exposure in individuals with COPD. former investigators of the SPIROMICS sites and reading centres: Neil E Alexis, PhD; Wayne H Anderson, PhD; R Graham Barr, MD, DrPH; Eugene R Bleecker, MD; Richard C Boucher, MD; Russell P Bowler, MD, PhD; Elizabeth E Carretta, MPH; Stephanie A Christenson, MD; Alejandro P Comellas, MD; Christopher B Cooper, MD, PhD; David J Couper, PhD; Gerard J Criner, MD; Ronald G Crystal, MD; Jeffrey L Curtis, MD; Claire M Doerschuk, MD; Mark T Dransfield, MD; Christine M Freeman, PhD; MeiLan K Han, MD, MS; Nadia N Hansel, MD, MPH; Annette T Hastie, PhD; Eric A Hoffman, PhD; Robert J Kaner, MD; Richard E Kanner, MD; Eric C Kleerup, MD; Jerry A Krishnan, MD, PhD; Lisa M LaVange, PhD; Stephen C Lazarus, MD; Fernando J Martinez, MD, MS; Deborah A Meyers, PhD; John D Newell Jr, MD; Elizabeth C Oelsner, MD, MPH; Wanda K O'Neal, PhD; Robert Paine, III, MD; Nirupama Putcha, MD, MHS; Stephen I Rennard, MD; Donald P Tashkin, MD Mary Beth Scholand, MD; J Michael Wells, MD; Robert A Wise, MD; and Prescott G Woodruff, MD, MPH. The project officers from the Lung Division of the National Heart, Lung, and Blood Institute were Lisa Postow, PhD, and Thomas Croxton, PhD, MD.

Contributors NNH, JDK, RDP, VSF, PJB, RGB and NA contributed to study design and drafting and review of the manuscript. AJG and LMP contributed to data collection, drafting and review of the manuscript. All other coauthors EB, RB, APC, MD, MKH, VK, JAK, CP, CBC, FM and PGW contributed to data collection and manuscript review.

Funding SPIROMICS AIR was supported by NIH NIEHS (R01ES023500). SPIROMICS was supported by contracts from the NIH/NHLBI (HHSN268200900013C, HHSN268200900014C, HHSN268200900015C, HHSN268200900016C, HHSN268200900017C, HHSN268200900018C, HHSN268200900019C, HHSN268200900020C), which were supplemented by contributions made through the Foundation for the NIH from AstraZeneca; Bellerophon Therapeutics; Boehringer-Ingelheim Pharmaceuticals, Inc; Chiesi Farmaceutici SpA; Forest Research Institute, Inc; GSK; Grifols Therapeutics, Inc; Ikaria, Inc; Nycomed $\mathrm{GmbH}$; Takeda Pharmaceutical Company; Novartis Pharmaceuticals Corporation; Regeneron Pharmaceuticals, Inc; and Sanofi.

Competing interests All authors have completed the ICMJE uniform disclosure form at www.icmje.org/coi_disclosure.pdf and declare: NNH has research grants from NIH/NIEHS and EPA, research grants and personal fees (advisory board) from AstraZeneca and GlaxoSmithKline; LMP and AJG have grants from NIH; RDP has personal fees from the Health Effects Institute; EB has grants from NHLBI/ $\mathrm{NIH}$, personal fees from consultancy and is involved in clinical trials administered through Wake Forest School of Medicine from Amgen, AstraZeneca-Medlmmune, Boehringer-Ingelheim, Genentech/Roche, GlaxoSmithKline, Novartis and Sanofi/ Regeneron, personal fees from Knopp, and clinical trials administered through Wake Forest School of Medicine from Janssen/Johnson \& Johnson, Pfizer and Teva; APC has non-financial support for consultancy through VIDA Diagnostics; MD has grants from $\mathrm{NIH}$ and the Department of Defense and personal fees for consultancy from AstraZeneca; MKH has personal fees from Boehringer-Ingelheim, Novartis, AstraZeneca, GlaxoSmithKline and Sunovian; VK has personal fees from Medscape (peer reviewer), CSA Medical (advisory board), American Board of Internal Medicine (Critical Care Medicine Committee chair), Gala Therapeutics (advisory board) and PneumRx; JAK has grants from NIH/NHLBl; CBC has grants and personal fees from Equinox Health Clubs and Spiration, a grant from Amgen, and personal fees from PulmonX, Boehringer-Ingelheim and GlaxoSmithKline; FM has a grant from NHLBl; PGW has a grant from Medlmmune and personal fees from Genentech/Roche, AstraZeneca, Novartis, Neostem and Janseen for consultancy; RGB has grants from $\mathrm{NIH}$, Foundation for the NIH and COPD Foundation; NA, VSF, RB, CP, PJB and JDK have nothing to disclose.

Patient consent Obtained.

Ethics approval Institutional Review Board.

Provenance and peer review Not commissioned; externally peer reviewed.

Open Access This is an Open Access article distributed in accordance with the Creative Commons Attribution Non Commercial (CC BY-NC 4.0) license, which permits others to distribute, remix, adapt, build upon this work non-commercially, and license their derivative works on different terms, provided the original work is properly cited and the use is non-commercial. See: http://creativecommons.org/ licenses/by-nc/4.0/

(c) Article author(s) (or their employer(s) unless otherwise stated in the text of the article) 2017. All rights reserved. No commercial use is permitted unless otherwise expressly granted.

\section{REFERENCES}

1. Adeloye D, Chua S, Lee C, et al. Global and regional estimates of COPD prevalence: systematic review and meta-analysis. J Glob Health 2015;5:020415. 
2. Hansel NN, McCormack MC, Kim V. The effects of air pollution and temperature on COPD. COPD 2016;13:372-9.

3. Keller JP, Olives C, Kim SY, et al. A unified spatiotemporal modeling approach for predicting concentrations of multiple air pollutants in the multi-ethnic study of atherosclerosis and air pollution. Environ Health Perspect 2015;123:301-9.

4. Leidy NK, Wilcox TK, Jones PW, et al. Standardizing measurement of chronic obstructive pulmonary disease exacerbations. Reliability and validity of a patient-reported diary. Am J Respir Crit Care Med 2011;183:323-9.

5. American Thoracic Society. Standardization of spirometry, 1994 update. Am J Respir Crit Care Med;1995:1107-36 .

6. Jones PW, Quirk FH, Baveystock CM, et al. A self-complete measure of health status for chronic airflow limitation. The St. George's respiratory questionnaire. Am Rev Respir Dis 1992;145:1321-7.

7. Jones PW, Harding G, Berry P, et al. Development and first validation of the COPD Assessment Test. Eur Respir J 2009;34:648-54.

8. Bestall JC, Paul EA, Garrod R, et al. Usefulness of the Medical Research Council (MRC) dyspnoea scale as a measure of disability in patients with chronic obstructive pulmonary disease. Thorax 1999;54:581-6.

9. ATS Committee on Proficiency Standards for Clinical Pulmonary Function Laboratories. ATS statement: guidelines for the six-minute walk test. Am J Respir Crit Care Med 2002;166:111-7.

10. Sieren JP, Newell JD, Barr RG, et al. SPIROMICS Protocol for multicenter quantitative computed tomography to phenotype the Lungs. Am J Respir Crit Care Med 2016;194.

11. Kulkarni NS, Prudon B, Panditi SL, et al. Carbon loading of alveolar macrophages in adults and children exposed to biomass smoke particles. Sci Total Environ 2005;345:23-30.

12. Belli AJ, Bose S, Aggarwal N, et al. Indoor particulate matter exposure is associated with increased black carbon content in airway macrophages of former smokers with COPD. Environ Res 2016;150:398-402.

13. Zandbergen PA. Influence of geocoding quality on environmental exposure assessment of children living near high traffic roads. BMC Public Health 2007;7:37.

14. Spalt EW, Curl CL, Allen RW, et al. Time-location patterns of a diverse population of older adults: the multi-ethnic study of atherosclerosis and air pollution (MESA Air). J Expo Sci Environ Epidemiol 2016;26:349-55.

15. Allen RW, Adar SD, Avol E, et al. Modeling the residential infiltration of outdoor PM(2.5) in the multi-ethnic study of atherosclerosis and air pollution (MESA Air). Environ Health Perspect 2012;120:824-30 .

16. Sampson PD, Szpiro AA, Sheppard L, et al. Pragmatic estimation of a spatio-temporal air quality model with irregular monitoring data. Atmos Environ 2011;45:6593-606.

17. Szpiro AA, Sampson PD, Sheppard L, et al. Predicting intra-urban variation in air pollution concentrations with complex Spatiotemporal dependencies. Environmetrics 2009;21:606-31.

18. Matte TD, Ross Z, Kheirbek I, et al. Monitoring intraurban spatial patterns of multiple combustion air pollutants in New York city: design and implementation. J Expo Sci Environ Epidemiol 2013;23:223-31.

19. Cohen MA, Adar SD, Allen RW, et al. Approach to estimating participant pollutant exposures in the multi-ethnic study of atherosclerosis and air pollution (MESA Air). Environ Sci Technol 2009:43:4687-93.

20. Dominici F, Peng RD, Bell ML, et al. Fine particulate air pollution and hospital admission for cardiovascular and respiratory diseases. JAMA 2006;295:1127-34.

21. Schwartz J. Air pollution and hospital admissions for respiratory disease. Epidemiology 1996;7:20-8.
22. Sunyer J. Urban air pollution and chronic obstructive pulmonary disease: a review. Eur Respir J 2001;17:1024-33.

23. Ackermann-Liebrich U, Leuenberger P, Schwartz J, et al. Lung function and long term exposure to air pollutants in Switzerland. study on air pollution and lung diseases in adults (SAPALDIA) team. Am J Respir Crit Care Med 1997:155:122-9.

24. Adar SD, Kaufman JD, Diez-Roux AV, et al. Air pollution and percent emphysema identified by computed tomography in the Multi-Ethnic study of Atherosclerosis. Environ Health Perspect 2015;123:144-51.

25. Ko FW, Tam W, Wong TW, et al. Temporal relationship between air pollutants and hospital admissions for chronic obstructive pulmonary disease in Hong Kong. Thorax 2007;62:780-5.

26. Peacock JL, Anderson HR, Bremner SA, et al. Outdoor air pollution and respiratory health in patients with COPD. Thorax 2011;66:591-6.

27. Naess $\varnothing$, Nafstad P, Aamodt G, et al. Relation between concentration of air pollution and cause-specific mortality: four-year exposures to nitrogen dioxide and particulate matter pollutants in 470 neighborhoods in Oslo, Norway. Am J Epidemiol 2007; $165: 435-43$.

28. Andersen ZJ, Hvidberg M, Jensen SS, et al. Chronic obstructive pulmonary disease and long-term exposure to traffic-related air pollution. Am J Respir Crit Care Med 2011:183:455-61.

29. Wood AM, Harrison RM, Semple S, et al. Outdoor air pollution is associated with rapid decline of lung function in alpha-1-antitrypsin deficiency. Occup Environ Med 2010;67:556-61.

30. Pope CA, Kanner RE. Acute effects of PM10 pollution on pulmonary function of smokers with mild to moderate chronic obstructive pulmonary disease. Am Rev Respir Dis 1993;147:1336-40.

31. de Hartog JJ, Ayres JG, Karakatsani A, et al. Lung function and indicators of exposure to indoor and outdoor particulate matter among asthma and COPD patients. Occup Environ Med 2010;67:2-10.

32. Karakatsani A, Analitis A, Perifanou D, et al. Particulate matter air pollution and respiratory symptoms in individuals having either asthma or chronic obstructive pulmonary disease: a European multicentre panel study. Environ Health 2012;11:75.

33. Langsetmo L, Platt RW, Ernst P, et al. Underreporting exacerbation of chronic obstructive pulmonary disease in a longitudinal cohort. Am J Respir Crit Care Med 2008;177:396-401.

34. Canova C, Dunster C, Kelly FJ, et al. PM10-induced hospital admissions for asthma and chronic obstructive pulmonary disease: the modifying effect of individual characteristics. Epidemiology 2012;23:607-15.

35. Aaron SD, Donaldson GC, Whitmore GA, et al. Time course and pattern of COPD exacerbation onset. Thorax 2012;67:238-43.

36. Klepeis NE, Nelson WC, Ott WR, et al. The National human activity pattern survey (NHAPS): a resource for assessing exposure to environmental pollutants. J Expo Anal Environ Epidemiol 2001:11:231-52.

37. Leech JA, Smith-Doiron M. Exposure time and place: do COPD patients differ from the general population? J Expo Sci Environ Epidemiol 2006;16:238-41.

38. Osman LM, Douglas JG, Garden C, et al. Indoor air quality in homes of patients with chronic obstructive pulmonary disease. Am J Respir Crit Care Med 2007:176:465-72.

39. Hansel NN, McCormack MC, Belli AJ, et al. In-home air pollution is linked to respiratory morbidity in former smokers with chronic obstructive pulmonary disease. Am J Respir Crit Care Med 2013;187:1085-90.

40. Bunn HJ, Dinsdale D, Smith T, et al. Ultrafine particles in alveolar macrophages from normal children. Thorax 2001;56:932-4.

41. You R, Lu W, Shan M, et al. Nanoparticulate carbon black in cigarette smoke induces DNA cleavage and Th17-mediated emphysema. Elife 2015;4:e09623. 